\title{
Stress-Reactive Rumination, Negative Cognitive Style, and Stressors in Relationship to Depressive Symptoms in Non-Clinical Youth
}

\author{
Lea Rood · Jeffrey Roelofs · Susan M. Bögels • \\ Cor Meesters
}

Received: 24 December 2010/ Accepted: 15 March 2011/Published online: 31 March 2011

(C) The Author(s) 2011. This article is published with open access at Springerlink.com

\begin{abstract}
The role of cognitive vulnerability in the development of depressive symptoms in youth might depend on age and gender. The current study examined cognitive vulnerability models in relationship to depressive symptoms from a developmental perspective. For that purpose, 805 youth (aged 10-18, 59.9\% female) completed self-report measures. Stress-reactive rumination was strongly related to depressive symptoms. Negative cognitive style (i.e., tendency to make negative inferences) in the domains of achievement and appearance was more strongly and consistently related to depressive symptoms in girls compared to boys. Negative cognitive style in the interpersonal domain was positively related to depressive symptoms in both girls and boys, except in early adolescent girls reporting few stressors. To conclude, the cognitive vulnerability-stress interaction may be moderated by the combination of age and gender in youth, which may explain inconsistent findings so far. Current findings highlight the importance of taking into account domain specifity when examining models of depression in youth.
\end{abstract}

L. Rood · J. Roelofs $(\bowtie) \cdot$ C. Meesters

Department of Clinical Psychological Science, Maastricht University, P.O. Box 616, 6200 MD Maastricht, The Netherlands

e-mail: J.Roelofs@maastrichtuniversity.nl

L. Rood

e-mail: L.Rood@maastrichtuniversity.nl

C. Meesters

e-mail: C.Meesters@maastrichtuniversity.nl

S. M. Bögels

Research Institute of Child Development and Education,

University of Amsterdam, P.O. Box 19268, 1000 GG

Amsterdam, The Netherlands

e-mail: S.M.Bogels@uva.nl
Keywords Adolescents - Cognitive style - Depressive symptoms $\cdot$ Repetitive thinking $\cdot$ Rumination

\section{Introduction}

Developmental models of depression in adolescence have conceptualized cognitive vulnerability within the context of a diathesis-stress account (see Hankin and Abramson 2001; Hyde et al. 2008), in which cognitive vulnerability represents the diathesis. The cognitive vulnerability-stress model proposes that cognitive vulnerability factors are more likely to lead to depression in the presence of stressors. A cognitive vulnerability factor that has been hypothesised to interact with stressors in the prediction of depression is negative cognitive style (see Abramson et al. 1989). Negative cognitive style can be defined as the general tendency to make negative attributions and inferences about the causes, consequences, and implications of stressful events. More specifically, these attributions and inferences include the tendencies to view (1) the causes of negative events as global and stable, (2) negative events as having many disastrous consequences, and (3) the self as flawed and deficient after the occurrence of negative events. Stressors in youth have been defined as "environmental events or chronic conditions that objectively threaten the physical and/or psychological health or wellbeing of individuals [...]" (Grant et al. 2003, p. 450). Stressful negative life events and daily hassles (generally taken together) have represented the stress-component in cognitive vulnerability-stress models in youth (e.g., Abela 2001; Abela and Payne 2003; Hankin et al. 2001). Major life events are related especially to the onset of depression (Brown and Harris 1978; Kendler et al. 2001; Kessler 1997; Monroe and Harkness 2005) whereas daily hassles 
predict increases in psychological symptoms (Kanner et al. 1981) and may be related to the recurrence of depression (see Monroe and Harkness 2005).

A variable closely related to negative cognitive style is stress-reactive rumination, which is defined as "the tendency to ruminate on the negative inferences following stressful events" (Robinson and Alloy 2003, p. 276). Alloy and colleagues (Alloy et al. 2000; Robinson and Alloy 2003) introduced the concept of stress-reactive rumination to explain the onset and duration of depression, hypothesising that the effect of negative inferences (i.e., a negative cognitive style) on depression is more detrimental when these inferences are actively rehearsed (i.e., ruminated upon). Indeed, Alloy and colleagues found that individuals who have a negative cognitive style, combined with a tendency to ruminate on negative inferences, were particularly vulnerable to develop depressive episodes (Alloy et al. 2000; Robinson and Alloy 2003). Whether stress-reactive rumination moderates the relationship between negative cognitive style and depressive symptoms has not been examined in youth to the authors' best knowledge. The examination of the potential interplay between two cognitive vulnerability factors, one reflecting negative thought content, and the other the repetition of the negative content, may contribute to knowledge on the pathogenesis of depression and on how to target cognitive vulnerability to depression in youth. Finally, stress-reactive rumination may worsen the effects of stressors on depressive symptoms in the context of a cognitive vulnerability-stress model. This hypothesis also has not yet been tested.

When testing cognitive models of depression in youth, developmental factors should be taken into account. Cognitive diatheses have been thought to become stable predictors of depressive symptoms during adolescence, when cognitive capacities are further developing and maturing (see Cole et al. 2008; Turner and Cole 1994). Recent longitudinal studies involving youth samples indicate that age might moderate the relationship between the cognitive variables and depressive symptoms (Cole et al. 2008; Turner and Cole 1994). Empirical support for cognitive vulnerability-stress models is stronger in adolescent samples compared to child samples (Abela and Hankin 2008; Joiner and Wagner 1995; Lakdawalla et al. 2007). The interaction between cognitive vulnerability and stressors may occur somewhere between the ages of 11 and 15 (see Cole et al. 2008; Hyde et al. 2008). Furthermore, Abela and Hankin (2008) have suggested that cognitive factors may be relatively independent factors in childhood, but may become more interrelated in adolescence, during which a solid combination of these factors may make an individual vulnerable to develop depressive symptoms. This may imply that stress-reactive rumination, negative cognitive style, and age interact in adolescence.

Studies so far have examined the moderating effect of age on cognitive variables, with age being indicative of the level of development or maturation. However, it may be interesting to examine another variable that may reflect the level of maturity more closely, i.e., puberty. Studies have shown that the gender difference in depression rates emerges in puberty, with girls reporting more depressive symptoms than boys (see Hankin et al. 2008). Pubertal status has been linked to the increase in depressive symptoms in girls (Angold and Costello 2006). Angold et al. (1998) found that after mid-puberty, girls had higher rates of clinical depression compared to boys. Age did not significantly moderate this relationship, which could suggest that the emergence of the gender difference in depression rates is caused by puberty-related, rather than age-related changes. The moderating role of pubertal status instead of age in the testing of cognitive vulnerability-stress models has not yet been examined to our knowledge.

Further, models explaining gender differences in depression have proposed that cognitive vulnerability factors combined with high levels of stressors may be related more strongly to depressive symptoms in girls compared to boys (see Hankin and Abramson 2001; Nolen-Hoeksema and Girgus 1994). Empirical support for the moderating role of gender is mixed. Prospective studies in child and early adolescent samples (range of mean ages of the samples: 8.9-12.9) have shown that cognitive vulnerability moderates the effects of stressors on depressive symptoms only in girls (Abela and McGirr 2007; partial support in Abela 2001), whereas other studies involving adolescents (range of mean ages: 11.9-18.1) have found support for a cognitive vulnerability-stress model only in boys (Hankin et al. 2001; Morris et al. 2008; Stone et al. 2010). In sum, findings indicate that the moderating roles of both age and gender, as well as their potential interplay, should be included in the examination of cognitive models of depression in youth. Finally, researchers (Hyde et al. 2008; Mezulis et al. 2002; Mezulis and Funasaki 2009) have argued that domain specificity of vulnerability factors should be taken into account when examining models of depression. Findings show that women have a stronger tendency to ruminate on stressors related to physical appearance and interpersonal problems than men (Mezulis et al. 2002), and may be more likely to develop negative cognitive styles in the domains of interpersonal relationships and physical appearance. How domain specificity of cognitive vulnerability factors is related to depressive symptoms in adolescence has not been examined yet from a developmental viewpoint. 


\section{The Current Study}

This study aimed to examine three cognitive vulnerability models for depressive symptoms in non-clinical youth from a developmental viewpoint. First, it was hypothesized that stress-reactive rumination would moderate (i.e., exacerbate) the relationship between negative cognitive style and depressive symptoms (Model 1). Second, stressreactive rumination was hypothesized to moderate (i.e., exacerbate) the relationship between stressors and depressive symptoms (Model 2). Third, it was hypothesized that negative cognitive style would moderate (i.e., exacerbate) the relationship between stressors and depressive symptoms (Model 3). Regarding domain specificity, it was explored whether different results would be obtained when examining specific domains of negative cognitive style instead of the aggregate score for negative cognitive style.

Age and gender were taken into account as potential moderators in the examination of these three cognitive models. More specifically, it was expected that cognitive vulnerability factors (negative cognitive style/stress-reactive rumination) and stressors would worsen each other's relationship with depressive symptoms more strongly as age increases. Furthermore, as evidence regarding the moderating role of gender is mixed (i.e., some studies show a significant interaction between cognitive vulnerability and stressors only in girls and other studies only in boys) the moderating role of gender was explored in combination with the moderating role of age. Further, it was examined whether pubertal status would be a more sensitive moderator in these models compared to age.

\section{Methods}

Participants and Procedure

Participants were recruited at 35 primary and 6 secondary schools in the southern regions of The Netherlands. Principals of schools were approached and informed about the purpose of the study. When given permission to recruit at their school, the researchers came into the classrooms during regular class and held a 10-min talk in front of all pupils. In this talk, the purpose of this study was explained and informed consent forms were handed out and returned 2 weeks later. On average, $25 \%$ of the children who were approached agreed to participate. We obtained written informed consent from all parents and from all children aged 12 and above, in accordance with formal regulations. A total number of 805 participants completed the questionnaires. Some had more than $10 \%$ missing values on one of the measures and were therefore excluded from that measure. As a consequence, sample size ranged between 751 and 805 across the various analyses.

The mean age of the sample was 12.4 years $(\mathrm{SD}=1.9$; age range 10-18); 59.9\% was female. Age at baseline was skewed towards the younger ages (\%boys/\%girls): $15 / 17 \%$ was age $10,25 / 22 \%$ was age $11,23 / 17 \%$ was age $12,15 / 15 \%$ was age $13,12 / 13 \%$ was age $14,7 / 9 \%$ was age 15 , and $4 / 6 \%$ was age $16-18$. About half of the participants $(47.8 \%, N=385)$ received secondary education, of which $38.2 \%(N=147)$ were in pre-university education, $37.1 \%$ $(N=143)$ in school of higher general secondary education, and $24.7 \%(N=95)$ in lower professional secondary education. Ethnicity was not reported, but considering the ethnic constellation of the southern regions of the Netherlands, it is acceptable to assume that about $95 \%$ of the sample were Caucasian. Participants completed a battery of questionnaires at home. They did not receive compensation for their participation. Little information is available on how the study's participants differed from those who did not participate. The proportion of the sample that exhibited clinically significant levels of depressive symptoms was $12.9 \%$ (CDI cut off score $\geq 16$; see Timbremont et al. 2004). The research protocol was approved by a local Institutional Review Board.

\section{Measures}

\section{Depressive Symptoms}

The Children's Depression Inventory (CDI; Kovacs 1981; Dutch/Flemish version: Timbremont and Braet 2001, 2002) is based on the Beck Depression Inventory for adults. The $\mathrm{CDI}$ is a widely used self-report questionnaire which aims to measure the level of depressive symptoms in children. For each of the 27 items three statements are given, of which the subject has to choose one (e.g., "I am sad sometimes/I am often sad/I am always sad") that represents best how he or she has been feeling the last 2 weeks. Reliability in terms of internal consistency is good and the convergent validity of the CDI is supported (Timbremont and Braet 2001).

\section{Stress-Reactive Rumination (from Here Referred to as "SR-Rumination")}

The Dutch version of the Stress-Reactive Rumination Scale for Children (SRRS-C) is a downward extension of the SRRS developed for adults (Robinson 1997; Robinson and Alloy 2003). The SRRS-C was translated into Dutch, and subsequently back translated by a native English speaker and then was approved by the original authors. The SRRS-C aims to measure the frequency of negative thoughts about negative inferences following stressful 
events (e.g., "I think about how the stressful event was totally my fault"). The SRRS-C consists of nine items which are scored on a four-point Likert type scale (i.e., $1=$ almost never, $2=$ sometimes, $3=$ often, $4=$ almost all the time). Reliability $(\alpha=.82)$ and concurrent criterion validity of the SRRS-C are adequate to good; furthermore, SR-rumination can meaningfully be distinguished from emotion-focused rumination and worry (Rood et al. 2010).

\section{Negative Cognitive Style (from Here Referred to as "NCS")}

The Adolescent Cognitive Styles Questionnaire (ACSQ; Hankin and Abramson 2002) measures inferential styles in response to negative events. The original ACSQ consists of 12 hypothetical negative event scenarios covering the domains of academic/scholar achievements and interpersonal relations. In the current study, we used a version which also contains a third domain particularly relevant for adolescence, i.e. "physical appearance" (4 items). Examples of hypothetical event scenarios in the different domains are: "You want to go to a big party, but nobody invites you" (interpersonal), "Someone says something bad about how you look" (appearance), and "You take a test and get a bad grade" (achievement). Each hypothetical event scenario is accompanied by five questions, measuring internal/external attribution of the cause, inferences about stability and globality of the cause, and inferences about consequences and self-worth, rated on a seven-point scale. An aggregate score can be computed by summing up scores on all scales, with high scores defining a high NCS. The psychometric properties (reliability, test-retest reliability, and construct validity) of the ACSQ are supported (Hankin and Abramson 2002).

\section{Stressors}

The Children's Life Events Scale (CLES; as described in Abela and Véronneau-McArdle 2002) is composed of two questionnaires. The first 37 items are derived from the Children's Hassles Scale (Kanner et al. 1987) and describe daily hassles (e.g. "You had to clean up your room"). Responses are rated on a four-point scale, with $0=$ "when it didn't happen"; 1 = "when it occasionally happened"; $2=$ "when it often happened"; and $3=$ "when it happened all the time". The other 22 items, taken from the Coddington Life Stress Scale (Coddington 1972), describe relatively serious life events (e.g., "Your mother or father lost her/his job"). One can answer "yes" or "no" dependent on whether the life event occurred the past year. For the current study the two scales were collapsed into one single scale labeled "stressors", which is consistent with previous studies (e.g., Abela and Sarin 2002). For that purpose, the daily hassles items were dichotomized, with original scores 1, 2 and 3 recoded in 1 ("it happened"), and original score 0 remaining 0 ("it didn't happen").

\section{Pubertal Status}

The Physical Development Scale (PDS; Petersen et al. 1988 ) is a self-report questionnaire measuring perceived pubertal status. The PDS consists of multiple choice questions regarding growth spurt, skin changes, and pubic hair. An example of an item is: "Have you noticed any skin changes?". The items have four answering options, ranging from " $1=$ not yet..." to " $4=$ seems completed". A high total score on the questionnaire indicates a high pubertal status. The version for girls also includes items on the menarche and breast growth, while the version for boys includes items on voice changes and facial hair growth. The PDS is acceptably reliable in terms of internal consistency; validity, however, needs further investigation (see for reviews Coleman and Coleman 2002; Schmitz et al. 2004). Studies have shown that youth are capable of making a rough estimation of their pubertal status (Bond et al. 2006; Coleman and Coleman 2002; Petersen et al. 1988; Schmitz et al. 2004). It should be emphasized that self-perception of pubertal status is measured rather than actual pubertal status (Dorn et al. 2006). The original (English) version was translated into Dutch for this study.

\section{Statistical Analysis}

The data were analysed using SPSS version 18.0. For individuals with less than $10 \%$ missing values on a single selfreport measure, a regression technique was used to impute the missing values by estimating the value on the basis of the scores of that individual on the remaining items, as well as on the scores of others on the item for which a value was missing. Cases with more than $10 \%$ missing values on one of the measures were excluded from that specific measure. Binary logistic regression analyses were performed to check whether scores on questionnaires were missing at random or missing not at random (i.e., whether missing scores could be explained by the independent and dependent variables). Missing ACSQ total scores were significantly predicted by age $(\operatorname{Exp} \beta=1.20, p=.04)$, indicating that the older the participant, the more likely the ACSQ was completed. The ACSQ was the last questionnaire in the battery and therefore may not have been completed by some of the younger participants due to tiredness or boredom.

Because the sample was nested within schools, the intraclass correlation was checked in order to determine whether intra-unit dependency needed be controlled for. The ICC indicated low homogeneity of depressive symptoms within schools $(\mathrm{ICC}=.02)$, which justified regular 
regression analyses. Before carrying out the analyses, assumptions were checked. The total scores on the CDI were not normally distributed and therefore underwent a square root transformation, resulting in skewness and kurtosis values between -1.0 and +1.0 (for all variables skewness range: -.01 to .90 ; kurtosis range: -1.10 to .50 ). Examination of plots of the standardized residuals against the standardized predicted values, partial plots, and normal probability plots of the residuals for each regression model indicated no violations of the assumptions of homogeneity of variances, homoscedastity, and linearity. All variables were standardized prior to creating interactions.

We carried out normal regression analyses with depressive symptoms as dependent variable. The models were tested separately from each other, following a top-down procedure starting with a full model (i.e., the four-way interaction) and subsequently eliminating interactions that were not significant. The starting models were as follows: (1) four-way interaction between NCS, SR-rumination, age, and gender; (2) four-way interaction between SR-rumination, stressors, age, and gender; and (3) four-way interaction between NCS, stressors, age, and gender. Domain specificity of NCS was examined by re-running the analyses for Models 1 and 3, with NCS in the domains of scholar achievement, interpersonal relations, and physical appearance separately (from here referred to as "NCS-achievement", "NCS-interpersonal", "NCS-appearance"), instead of the aggregate score for NCS. Finally, we tested alternative models repeating the same series of analyses with pubertal status instead of age.

\section{Results}

\section{General Findings}

Descriptive statistics for the total sample as well as for boys and girls separately are presented in Table 1 , together with the reliability coefficients of all measures. All questionnaires showed good reliability in terms of internal consistency. Girls scored higher on SR-rumination and pubertal status compared to boys. The ACSQ subscales stability, globality, consequences, and self-worth were substantially related to depressive symptoms $(r=.44-51)$, whereas the internality scale correlated low with depressive symptoms $(r=.17)$. All ACSQ subscales were highly interrelated $(r=.42-.86)$. For the internality scale the correlations with depressive symptoms and the other ACSQ subscales were substantially lower than for the other subscales $(p<.001)$. Therefore, the internality dimension was not included in the composite scale of the ACSQ. SR-rumination, NCS, and stressors were all strongly associated with depressive symptoms; while age and pubertal status were modestly related to depressive symptoms (see Table 2).
Model 1: NCS Moderated by SR-Rumination

The interaction between NCS and SR-rumination was not significant, nor did age and gender moderate the relationships between the variables (independently and in interaction with each other) and depressive symptoms. Only the main effects of SR-rumination and NCS were significant, indicating that both variables are related to depressive symptoms independently of each other. Age and sex were not significantly related to depressive symptoms when controlling for NCS and SR-rumination. The final (reduced) model is displayed in Table 3. The analyses with NCS per domain yielded almost identical findings, i.e., significant main effects were found for NCS per domain and SR-rumination. Results are therefore not reported.

\section{Model 2: Stressors Moderated by SR-Rumination}

The interaction between stressors and SR-rumination was not significant, nor did age and gender moderate the relationships between the variables and depressive symptoms. Only the main effects of SR-rumination and stressors were significant, indicating that both variables were independently related to depressive symptoms. The final model is displayed in Table 3.

\section{Model 3: Stressors Moderated by NCS}

The four-way interaction between NCS, stressors, gender, and age was significant $(\beta=-.12, p=.02)$, see Table 3 . The four-way interaction was examined more closely by splitting the data on high/low age (mean $\pm 1 \mathrm{SD}$ ) and on gender. The interaction term between NCS and stressors was significant only in middle to late adolescent boys ( $\beta=.33, p=.03$ ). NCS related to depressive symptoms at the level of a trend in middle to late adolescent boys reporting many (mean +1 SD) stressors $(\beta=.81$, $p=.10$ ), whereas this relationship was not significant in middle to late adolescent boys reporting few (mean $-1 \mathrm{SD}$ ) stressors $(\beta=.30, p=.37)$. In early adolescent boys, stressors were significantly associated with depressive symptoms $(\beta=.59, p=.001)$, whereas NCS was not $(\beta=.11, p=.39)$. In girls, NCS $(\beta=.41, p=.001)$ and stressors $(\beta=.39, p=.001)$ were independently related to depressive symptoms, meaning that the strength of the relationship between one variable and depressive symptoms is not conditional on the other variable.

Regarding the domain specificity of $\mathrm{NCS},{ }^{1}$ results showed a significant four-way interaction between

\footnotetext{
${ }^{1} T$ tests revealed no gender differences on the scores on NCS in the different domains. Reliability was sufficient: $\alpha=.71$ for NCSachievement; $\alpha=.73$ for NCS-interpersonal; $\alpha=.76$ for NCSappearance.
} 
Table 1 Descriptive statistics (raw means and standard deviations), internal consistency ratings, and gender differences $(N=754-805)$

\begin{tabular}{|c|c|c|c|c|c|c|c|c|c|}
\hline \multirow[t]{2}{*}{ Variable } & \multicolumn{3}{|c|}{ Total sample } & \multicolumn{2}{|l|}{ Girls } & \multicolumn{2}{|l|}{ Boys } & \multirow[t]{2}{*}{$t$} & \multirow[t]{2}{*}{$d f$} \\
\hline & Mean & SD & $\alpha$ & Mean & SD & Mean & SD & & \\
\hline 1. Depressive symptoms (CDI) & 8.0 & 6.3 & .86 & 8.3 & 6.6 & 7.5 & 5.9 & 1.48 & 786 \\
\hline 2. Stress-reactive rumination (SRRS-C) & 16.7 & 5.1 & .88 & 17.2 & 5.2 & 16.0 & 4.8 & $3.19 *$ & 792 \\
\hline 3. Negative cognitive style (ACSQ) & 122.5 & 51.5 & $.89^{\mathrm{a}}$ & 124.6 & 51.4 & 119.4 & 51.6 & 1.38 & 752 \\
\hline 4. Stressors (CLES) & 26.2 & 7.9 & .85 & 26.1 & 7.7 & 26.5 & 8.3 & .76 & 800 \\
\hline 5. Pubertal status (PDS) & 11.3 & 4.2 & .84 & 12.4 & 4.2 & 9.8 & 3.5 & $9.22 *$ & 764 \\
\hline 6. Age & 12.4 & 1.9 & - & 12.4 & 1.9 & 12.3 & 1.7 & 1.23 & 736 \\
\hline
\end{tabular}

CDI Children's Depression Inventory, SRRS-C Stress-Reactive Rumination Scale for Children, ACSQ Adolescent Cognitive Styles Questionnaire, CLES Children's Life Events Scale, PDS Physical Development Scale

$* p<.001$

a The reliability coefficient of the aggregate score of the ACSQ was computed by averaging the reliability coefficients for the inferential styles (without internality) separately

Table 2 Pearson correlation coefficients between the (if necessary transformed) variables $(N=753-805)$

\begin{tabular}{llllll}
\hline & 1. & 2. & 3. & 4. & 5. \\
\hline 1. Depressive symptoms (CDI) & - & & & \\
2. Stress-reactive rumination (SRRS-C) & $.59^{* *}$ & - & & \\
3. Negative cognitive style (ACSQ) & $.51^{* *}$ & $.45^{* *}$ & - & & \\
4. Stressors (CLES) & $.55^{* *}$ & $.42^{* *}$ & $.35^{* *}$ & - & \\
5. Pubertal status (PDS) & $.16^{* *}$ & $.21^{* *}$ & $.17^{* *}$ & .04 & - \\
6. Age & $.12^{* *}$ & $.17^{* *}$ & $.14^{* *}$ & .01 & $.75^{* *}$ \\
7. Gender & .05 & $.11^{* *}$ & .05 & -.03 & $.30^{* *}$ \\
\hline
\end{tabular}

CDI Children's Depression Inventory, SRRS-C Stress-Reactive Rumination Scale for Children, ACSQ Adolescent Cognitive Styles Questionnaire, CLES Children's Life Events Scale, PDS Physical Development Scale

$* p<.05 ; * * p \leq .001$ (two-tailed)

stressors, NCS-achievement, age, and gender $(\beta=-.11$, $p=.02)$ in a similar way as with the aggregate NCS: NCSachievement and depressive symptoms were significantly related in middle to late adolescent boys reporting many stressors $(\beta=.99, p=.001)$, but not in those reporting few stressors $(\beta=.02, p=.95)$. In early adolescent boys, stressors $(\beta=.59, p<.001)$ were significantly related to depressive symptoms, whereas NCS-achievement was not $(\beta=.13, p=.31)$. In girls, NCS-achievement $(\beta=.35$, $p<.001)$ and stressors $(\beta=.41, p<.001)$ were related to depressive symptoms, independently of each other.

The four-way interaction between NCS-interpersonal, stressors, age, and gender was significant $(\beta=-.10$, $p=.04)$. The interaction was split on gender and next on high/low (mean $\pm 1 \mathrm{SD}$ ) events. The interaction between NCS-interpersonal and age was significant for girls reporting few stressors $(\beta=.36, p=.02)$, indicating that NCS-interpersonal and depressive symptoms were positively related in middle to late adolescent girls reporting few stressors $(\beta=.59, p=.30)$, and negatively related in early adolescent girls reporting few stressors $(\beta=-.30$, $p=.47$ ). NCS-interpersonal and depressive symptoms were significantly related in girls reporting many stressors $(\beta=.49, p<.001)$. NCS-interpersonal $(\beta=.26, p<.001)$ and stressors $(\beta=.47, p<.001)$ were independently related to depressive symptoms in boys.

The four-way interaction with NCS-appearance was not significant; instead, NCS-appearance interacted with gender $(\beta=.12, p=.01)$, indicating a stronger relationship between NCS-appearance and depressive symptoms in girls $(\beta=.35, p=.001)$ compared to boys $(\beta=.22$, $p=.001)$.

\section{Pubertal Status Versus Age}

The analyses with pubertal status instead of age yielded different results with regard to the main models. The fourway interaction between NCS, stressors, pubertal status, and gender approached significance $(\beta=-.10, p=.08)$, indicating that the interaction between NCS and stressors was only significant in boys who perceived their pubertal status as high $(\beta=.42, p=.007)$. NCS was more strongly related to depressive symptoms in boys with high pubertal 
Table 3 Results of the final regression models in association with depressive symptoms $(N=752-785)$

\begin{tabular}{|c|c|c|c|c|c|c|}
\hline Variable & St. $\beta$ & SE & $t$ & $p$ & Adj. $R^{2}$ & $F$ \\
\hline \multicolumn{7}{|c|}{ Model 1: Negative cognitive style moderated by stress-reactive rumination } \\
\hline & & & & & .41 & 133.19 \\
\hline Gender & -.01 & .03 & -.47 & .64 & & \\
\hline Age & -.01 & .03 & -.51 & .61 & & \\
\hline Negative cognitive style (ACSQ) & .32 & .03 & 10.13 & $<.001$ & & \\
\hline Stress-reactive rumination (SRRS-C) & .44 & .03 & 14.02 & $<.001$ & & \\
\hline
\end{tabular}

Model 2: Stressors moderated by stress-reactive rumination

$\begin{array}{lcccc}\text { Gender } & & & & \\ \text { Age } & .01 & .03 & .31 & .76 \\ \text { Stress-reactive rumination (SRRS-C) } & .04 & .03 & 1.57 & .12 \\ \text { Stressors (CLES) } & .42 & .03 & 14.20 & <.001 \\ & .37 & .03 & 12.66 & <.001\end{array}$

.45

163.54

Model 3: Stressors moderated by negative cognitive style

\begin{tabular}{|c|c|c|c|c|c|c|}
\hline Gender & .05 & .03 & 1.70 & .09 & & \\
\hline Age & -.01 & .05 & -.10 & .92 & & \\
\hline Negative cognitive style (ACSQ) & .28 & .05 & 6.09 & $<.001$ & & \\
\hline Stressors (CLES) & .42 & .04 & 9.62 & $<.001$ & & \\
\hline Neg. cogn. style $\times$ Gender & .11 & .05 & 2.28 & .02 & & \\
\hline Neg. cogn. style $\times$ Age & .08 & .05 & 1.51 & .13 & & \\
\hline Gender $\times$ Age & .08 & .05 & 1.55 & .12 & & \\
\hline Stressors $\times$ Age & -.03 & .05 & -.64 & .52 & & \\
\hline Stressors $\times$ Gender & .002 & .04 & .04 & .97 & & \\
\hline Neg. cogn. style $\times$ Stressors & .07 & .04 & 1.68 & .09 & & \\
\hline Stressors $\times$ Age $\times$ Gender & -.04 & .05 & -.79 & .43 & & \\
\hline Stressors $\times$ Neg. cogn. style $\times$ Gender & -.04 & .04 & -.92 & .36 & & \\
\hline Stressors $\times$ Neg. cogn. style $\times$ Age & .08 & .05 & 1.52 & .13 & & \\
\hline \multirow[t]{2}{*}{ Neg. cogn. style $\times$ Age $\times$ Gender } & .003 & .05 & .06 & .96 & \multirow{3}{*}{.43} & \\
\hline & & & & & & 2.22 \\
\hline Stressors $\times$ Neg cogn style $\times$ Age $\times$ Gender & -.12 & .05 & -2.38 & .02 & & \\
\hline
\end{tabular}

ACSQ Adolescent Cognitive Styles Questionnaire, SRRS-C Stress-Reactive Rumination Scale for Children, CLES Children's Life Events Scale

status that reported many (mean $+1 \mathrm{SD})$ stressors $(\beta=.73$, $p=.16)$ compared to boys with high pubertal status reporting few stressors $(\beta=.21, p=.74)$. In boys who reported low pubertal status, both NCS $(\beta=.48, p=.001)$ and stressors $(\beta=.27, p=.002)$ were significantly associated with depressive symptoms. The relationship between NCS and depressive symptoms was moderated by pubertal status in both Model $1(\beta=.07, p=.01)$ and Model 3 $(\beta=.07, p=.01)$, indicating that NCS was more strongly related in participants reporting high pubertal status (mean $+1 \mathrm{SD} ; \beta=.68, p=.001)$ compared to participants reporting low pubertal status (mean $-1 \mathrm{SD}, \beta=.47$, $p=.001)$. Next to SR-rumination and stressors, pubertal status was modestly related to depressive symptoms $(\beta=.06, p=.03)$, indicating that participants reported more depressive symptoms as they perceived their pubertal status as higher.

\section{Discussion}

Stress-reactive rumination in combination with negative cognitive style may predict onset of depression in adults (Robinson and Alloy 2003). Not much is known about whether these two cognitive vulnerability factors interact in relationship to depressive symptoms in youth. Furthermore, research has shown that cognitive vulnerability-stress interactions in relationship to depressive symptoms emerge somewhere between the ages of 11-15 (Hyde et al. 2008). Studies suggest that the interaction between cognitive 
vulnerability and stressors may function differently in girls and boys during adolescence; however, evidence is inconsistent and may point to moderation by a combination of age and gender. This study aimed to examine three cognitive vulnerability models for depressive symptoms in non-clinical youth from a developmental viewpoint. The first model proposes that stress-reactive rumination moderates the relationship between negative cognitive style and depressive symptoms; the second model hypothesizes that stress-reactive rumination moderates the relationship between stressors and depressive symptoms; and the third model hypothesizes that negative cognitive style moderates the relationship between stressors and depressive symptoms. The potentially moderating effects of age, pubertal status, and gender were examined in all models. Domain specificity of negative cognitive style was explored.

Stress-reactive rumination ("SR-rumination") was related to depressive symptoms, independently of negative cognitive style ("NCS") or stressors, of which main effects were significant in both boys and girls. Second, NCS and stressors were both related to depressive symptoms in girls, independently of each other. The relationship between NCS and depressive symptoms approached level of significance in middle to late adolescent boys, but only in the presence of many stressors, supporting a cognitive vulnerability-stress model in middle to late adolescent boys. However, the examination of domain specificity of NCS yielded different results: NCS in the appearance domain was more strongly related to depressive symptoms in girls compared to boys, indicating that negative attributions and inferences about appearance may be associated with depressive symptoms in girls particularly. Furthermore, NCS in the interpersonal domain was related to depressive symptoms in boys and girls, except in early adolescent girls reporting few stressors, thus supporting a cognitive vulnerability-stress model in early adolescent girls.

With regard to the extension of the model of Robinson and Alloy (2003) to a youth sample, findings showed that NCS and SR-rumination accounted for a significant portion of the variance in depressive symptoms independently of each other. Our findings are thus not in line with Robinson and Alloy (2003) and Alloy et al. (2000), who found that SR-rumination worsens the effects of NCS on depression in adults. NCS and SR-rumination may not yet interact in youth because rumination has not stabilised yet in middle adolescence (Hankin 2008).

The finding that SR-rumination did not moderate the relationship between stressors and depressive symptoms is inconsistent with earlier studies demonstrating moderation of stressors by general forms of rumination (Kraaij et al. 2003; Skitch and Abela 2008). An explanation might be that SR-rumination is specifically focused on negative inferences and attributions and as such, is hypothesized to worsen the effect of NCS rather than the effect of stressors. One may argue that SR-rumination does not worsen the relationship between stressors and depressive symptoms in participants that do not have a highly NCS, suggesting a three-way interaction between these variables. Therefore, the three-way interaction between NCS, SR-rumination, and stressors was tested post-hoc, which was not significant. More research is needed to examine the possible interaction between NCS, SR-rumination, and stressors, for example in prospective high-risk designs.

Current findings provide support for a cognitive vulnerability-stress model (indicating that the aggregate NCS was only related to depressive symptoms in combination with many stressors) in middle to late adolescent boys, but not in girls and early adolescent boys. These findings are partially consistent with Cole et al. (2008) and Turner and Cole (1994) regarding the moderating role of age. However, present findings show that the moderating role of age only appeared in boys (and thus depended on gender). These findings are partially consistent with studies supporting the cognitive vulnerability-stress model for boys only (Hankin et al. 2001; Stone et al. 2010). It is important to note that the prospective studies of Hankin et al. and Stone et al. were conducted with middle to late adolescents, whereas other studies that found support for the interaction only in girls examined younger samples (e.g., Abela and McGirr 2007). Thus, current findings suggest that inconsistent results regarding the cognitive vulnerability-stress model in youth so far may be due to the moderating role of gender being dependent on age.

Current findings implicate that middle to late adolescent boys with a high NCS may only be vulnerable to develop depressive symptoms when experiencing many stressors, whereas girls with a high NCS may be vulnerable to depressive symptoms even without experiencing stressors. This might explain why girls after the age of 13 are more vulnerable to develop depressive symptoms compared to boys (see Kessler 2003; Kuehner 2003). Current findings regarding domain specificity also suggest that the moderating roles of age and gender depend on which domain of cognitive vulnerability is examined in interaction with stressors, supporting the plea of Hyde et al. (2008) and Mezulis et al. (2002) for the importance of examining domain specificity of cognitive vulnerability factors in developmental models of depression. To conclude, the cognitive vulnerability-stress interaction may be moderated by the combination of age and gender in youth, which may explain inconsistent findings so far.

\section{Age Versus Pubertal Status}

When controlling for SR-rumination and stressors, age was not significantly associated with depressive symptoms; 
whereas pubertal status was, indicating that depressive symptoms increase as pubertal status increases. The twoway interaction age (or pubertal status) by gender (included in all models under test) was not significant; whereas it would be expected that girls report more depressive symptoms as level of maturation (age/pubertal status) increases compared to boys. Results showed that although the four-way interaction between NCS, stressors, gender, and age was significant while the four-way interaction with pubertal status was marginally significant, the interpretation of these interactions was largely similar, i.e., NCS and depressive symptoms were significantly related only in the presence of many stressors in middle to late adolescent boys (or in boys reporting a high pubertal status).

In the model with SR-rumination, the relationship between NCS and depressive symptoms was stronger in adolescents who perceived their pubertal status as high, whereas age did not moderate this relationship. Perceived pubertal status, reflecting the subjective experience of morphological changes related to puberty (Angold and Costello 2006), may be a more sensitive moderator of NCS than age. However, contrary to age, how pubertal status is perceived and reported may also be influenced by depressive symptoms. When examining models of depression from a developmental perspective, age may be preferred over pubertal status, as age is a less complex variable. However, the current results do not seem to rule out that pubertal status may have additional value in examining cognitive models in youth.

\section{Strengths and Limitations}

This study has notable strengths that concern the large sample size, the wide age range, and the introduction of SR-rumination. The large sample size allows testing higher-order interactions, and thus testing models from a developmental perspective by including the potentially moderating roles of age and gender. The age range of the study sample captures the transition from childhood to adolescence and covers all phases of pubertal development. Theoretically, the introduction of SR-rumination is novel and contributes to existing research on cognitive vulnerability in youth. Moreover, the moderating role of SRrumination was examined in two models. Furthermore, the inclusion of pubertal status as an alternative to age is explored. Finally, examining domain specificity of NCS in youth is a new important avenue of research which can shed more light on the development of the gender difference in depressive symptoms.

The most important limitations of the current study concern the reliance on self-report measures, the crosssectional design, and the representativeness of the sample. A problem with the Coddington Life Events Scale (and the
Daily Hassles subscale in particular) may be that this selfreport measure may reflect the self-perceived experience of stressors rather than actual experienced stressors. However, Wagner et al. (2006) demonstrated that ratings on the CLES (assessing stressful life events and daily hassles) did not differ from an objectively rated interview assessing stressful life events in terms of over-reporting as a function of depression. Another limitation is the cross-sectional design, which merely allows drawing conclusions on associations between variables. Moreover, problematic issues such as construct overlap and shared method variance cannot be adequately handled. Furthermore, the low consent rates may have introduced a certain bias in the current sample, limiting the extent to which current results can be generalised to the Dutch youth population and to clinically depressed youth. Therefore, future research should focus on examining these relationships in representative community samples and in clinically depressed youth.

\section{Clinical and Theoretical Implications}

The findings from the current study may have some implications for future research and clinical practice. For future research, it would be interesting to investigate the developmental nature of the models using longitudinal designs, taking into account domain specificity of vulnerability factors. Prospective low/high-risk designs and experimental research can shed more light on causal relationships between stressors, SR-rumination, NCS, and depressive symptoms. With respect to clinical implications, we recommend that psychological treatment of depressive symptoms in youth should target ruminative thinking, and focus on altering NCS, both of which can be emphasized in cognitive therapy; and improve problem-solving or coping with stressors, which is targeted in behavioral activation therapy (Dimidjian et al. 2006). An interesting new approach to the treatment of depressive symptoms is mindfulness-based therapy (see Segal et al. 2002), which helps dealing with ruminative thinking and NCS. There is evidence that mindfulness techniques incorporated into dialectic behavior therapy are helpful in decreasing suicidality and depressed mood in depressed adolescents (Miller et al. 2007).

\section{Final Conclusion}

Stress-reactive rumination was strongly related to depressive symptoms. The strength of this relationship was similar for boys and girls, and did not differ as a function of age. Stress-reactive rumination did not moderate the effects of negative cognitive style, nor the effects of stressors in the association with depressive symptoms. Stress-reactive rumination and negative cognitive style may not interact in youth as cognitive vulnerability factors may not have 
stabilised yet. Negative cognitive style in the domains of achievement and appearance was more strongly and consistently related to depressive symptoms in girls compared to boys, independently of stressors. Negative cognitive style in the interpersonal domain was related to depressive symptoms in both girls and boys, except for early adolescent girls reporting few stressors, thus supporting a diathesis-stress pattern only in early adolescent girls. Negative cognitive style in the achievement domain was only significantly related to depressive symptoms in middle to late adolescent boys reporting many stressors, thus supporting a diathesis-stress pattern only in older boys. Moderation by pubertal status instead of age yielded slightly different results, that is, in the model with stress-reactive rumination, the relationship between negative cognitive style and depressive symptoms was stronger in adolescents who perceived their pubertal status as high, whereas age did not moderate this relationship. Current findings highlight the importance of taking into account domain specifity of vulnerability factors in the examination of developmental models of depression in youth.

Acknowledgments This research was supported by an Innovational Research Incentive VENI grant (451-05-019) of the Foundation for Behavioural and Educational Sciences of the Netherlands Organization for Scientific Research (NWO), awarded to the second author. The authors declare that they have no conflict of interest.

Open Access This article is distributed under the terms of the Creative Commons Attribution Noncommercial License which permits any noncommercial use, distribution, and reproduction in any medium, provided the original author(s) and source are credited.

\section{References}

Abela, J. R. Z. (2001). The hopelessness theory of depression: A test of the diathesis-stress and causal mediation components in third and seventh grade children. Journal of Abnormal Child Psychology, 29, 241-254.

Abela, J. R. Z., \& Hankin, B. L. (2008). Cognitive vulnerability to depression in children and adolescents: A developmental psychopathology perspective. In J. R. Z. Abela \& B. L. Hankin (Eds.), Handbook of depression in children and adolescents (pp. 35-78). New York: The Guilford Press.

Abela, J. R. Z., \& McGirr, A. (2007). Operationalizing cognitive vulnerability and stress from the perspective of the hopelessness theory: A multi-wave longitudinal study of children of affectively ill parents. British Journal of Clinical Psychology, 46, 377-395.

Abela, J. R. Z., \& Payne, A. V. L. (2003). A test of the integration of the hopelessness and self-esteem theories of depression in schoolchildren. Cognitive Therapy and Research, 27, 519-535.

Abela, J. R. Z., \& Sarin, S. (2002). Cognitive vulnerability to hopelessness depression: A chain is only as strong as its weakest link. Cognitive Therapy and Research, 26, 811-829.

Abela, J. R. Z., \& Véronneau-McArdle, M.-H. (2002). The relationship between self-complexity and depressive symptoms in third and seventh grade children: A short-term longitudinal study. Journal of Abnormal Child Psychology, 30, 155-166.
Abramson, L. Y., Metalsky, G., \& Alloy, L. B. (1989). Hopelessness depression: A theory-based subtype of depression. Psychological Review, 96, 358-372.

Alloy, L. B., Abramson, L. Y., Hogan, M. E., Whitehouse, W. G., Rose, D. T., Robinson, M. S., et al. (2000). The TempleWisconsin cognitive vulnerability to depression project: Lifetime history of axis I psychopathology in individuals at high and low cognitive risk for depression. Journal of Abnormal Psychology, 109, 403-418.

Angold, A., \& Costello, E. J. (2006). Puberty and depression. Child and Adolescent Psychiatric Clinics of North America, 15, 919-937.

Angold, A., Costello, E., \& Worthman, C. (1998). Puberty and depression: The roles of age, pubertal development and pubertal timing. Psychological Medicine, 28, 51-61.

Bond, L., Clements, J., Bertalli, N., Evans-Whipp, T., McMorris, B. J., Patton, G. C., et al. (2006). A comparison of self-reported puberty using the Pubertal development scale and the sexual maturation scale in a school-based epidemiologic survey. Journal of Adolescence, 29, 709-720.

Brown, G. W., \& Harris, T. O. (1978). Social origins of depression: A study of psychiatric disorder in women. New York: Free Press.

Coddington, R. D. (1972). The significance of life events as etiologic factors in the diseases of children, II: A study of a normal population. Journal of Psychosomatic Research, 16, 205-213.

Cole, D. A., Ciesla, J. A., Dallaire, D. H., Jacquez, F. M., Pineda, A. Q., LaGrange, B., et al. (2008). Emergence of attributional style and its relation to depressive symptoms. Journal of Abnormal Psychology, 117, 16-31.

Coleman, L., \& Coleman, J. (2002). The measurement of puberty: A review. Journal of Adolescence, 25, 535-550.

Dimidjian, S., Hollon, S. D., Dobson, K. S., Schmaling, K. B., Kohlenberg, R. J., Addis, M. E., et al. (2006). Randomized trial of behavioral activation, cognitive therapy, and antidepressant medication in the acute treatment of adults with major depression. Journal of Consulting and Clinical Psychology, 74, 658-670.

Dorn, L. D., Dahl, R. E., Woodward, H. R., \& Biro, F. (2006). Defining the boundaries of early adolescence: A user's guide to assessing pubertal status and pubertal timing in research with adolescents. Applied Developmental Science, 10, 30-56.

Grant, K. E., Compas, B. E., Stuhlmacher, A. F., Thurm, A. E., McMahon, S. D., \& Halpert, J. A. (2003). Stressors and child and adolescent psychopathology: Moving from markers to mechanisms of risk. Psychological Bulletin, 129, 447-466.

Hankin, B. L. (2008). Stability of cognitive vulnerabilities to depression: A short-term prospective multiwave study. Journal of Abnormal Psychology, 117(2), 324-333.

Hankin, B. L., \& Abramson, L. Y. (2001). Development of gender differences in depression: An elaborated cognitive vulnerabilitytransactional stress theory. Psychological Bulletin, 127, 773-796.

Hankin, B. L., \& Abramson, L. Y. (2002). Measuring cognitive vulnerability to depression in adolescence: Reliability, validity, and gender differences. Journal of Clinical Child and Adolescent Psychology, 31, 491-504.

Hankin, B. L., Abramson, L. Y., \& Siler, M. (2001). A prospective test of the hopelessness theory of depression in adolescence. Cognitive Therapy and Research, 25, 607-632.

Hankin, B. L., Wetter, E., \& Cheeley, C. (2008). Sex differences in child and adolescent depression: A developmental psychopathological approach. In J. R. Z. Abela \& B. L. Hankin (Eds.), Handbook of depression in children and adolescents (pp. 377-414). New York: The Guilford Press.

Hyde, J. S., Mezulis, A. H., \& Abramson, L. Y. (2008). The ABCs of depression: Integrating affective, biological, and cognitive 
models to explain the emergence of the gender difference in depression. Psychological Review, 115, 291-313.

Joiner, T. E., \& Wagner, K. D. (1995). Attributional style and depression in children and adolescents: A meta-analytic review. Clinical Psychology Review, 15, 777-798.

Kanner, A. D., Coyne, J. C., Schaefer, C., \& Lazarus, R. S. (1981). Comparison of two modes of stress measurement: Daily hassles and uplifts versus major life events. Journal of Behavioral Medicine, 4, 1-39.

Kanner, A. D., Feldman, S. S., Weinberger, D. A., \& Ford, M. E. (1987). Uplifts, hassles, and adaptational outcomes in early adolescents. Journal of Early Adolescence, 7, 371394.

Kendler, K. S., Thornton, L. M., \& Gardner, C. O. (2001). Genetic risk, number of previous depressive episodes, and stressful life events in predicting onset of major depression. American Journal of Psychiatry, 158, 582-586.

Kessler, R. C. (1997). The effects of stressful life events on depression. Annual Review of Psychology, 48, 191-214.

Kessler, R. C. (2003). Epidemiology of women and depression. Journal of Affective Disorders, 74, 5-13.

Kovacs, M. (1981). Rating scales to assess depression in school-aged children. Acta Paedopsychiatrica, 46, 305-315.

Kraaij, V., Garnefski, N., de Wilde, E. J., Dijkstra, A., Gebhardt, W., Maes, S., et al. (2003). Negative life events and depressive symptoms in late adolescence: Bonding and cognitive coping as vulnerability factors? Journal of Youth and Adolescence, 32, 185-193.

Kuehner, C. (2003). Gender differences in unipolar depression: An update of epidemiological findings and possible explanations. Acta Psychiatrica Scandinavia, 108, 163-174.

Lakdawalla, Z., Hankin, B. L., \& Mermelstein, R. (2007). Cognitive theories of depression in children and adolescents: A conceptual and quantitative review. Clinical Child and Family Psychological Review, 10, 1-24.

Mezulis, A. H., Abramson, L. Y., \& Hyde, J. S. (2002). Domain specificity of gender differences in rumination. Journal of Cognitive Psychotherapy: An International Quarterly, 16, 421-433.

Mezulis, A. H., \& Funasaki, K. (2009). Modeling the gender difference in depression: A commentary on Cambron, Acitelli, and Pettit. Sex Roles, 61, 762-768.

Miller, A. L., Rathus, J. H., \& Linehan, M. M. (2007). Dialectical behavior therapy with suicidal adolescents. New York: The Guilford Press.

Monroe, S. M., \& Harkness, K. L. (2005). Life stress, the "kindling" hypothesis, and the recurrence of depression: Considerations from a life stress perspective. Psychological Review, 112, $417-445$

Morris, M. C., Ciesla, J. A., \& Garber, J. (2008). A prospective study of the cognitive-stress model of depressive symptoms in adolescents. Journal of Abnormal Psychology, 117, 719734.

Nolen-Hoeksema, S., \& Girgus, J. S. (1994). The emergence of gender differences in depression during adolescence. Psychological Bulletin, 115, 424-443.

Petersen, A., Crockett, L., Richards, M., \& Boxer, A. (1988). A selfreport measure of pubertal development: Reliability, validity, and initial norms. Journal of Youth and Adolescence, 17, $117-133$

Robinson, M. (1997). The role of negative cognitive style and stressreactive rumination on negative inferences in the etiology of depression: Empirical investigation and clinical implications. Unpublished doctoral dissertation, Temple University.
Robinson, M., \& Alloy, L. (2003). Negative cognitive styles and stress-reactive rumination interact to predict depression: A prospective study. Cognitive Therapy and Research, 27, 275-292.

Rood, L., Roelofs, J., Bögels, S. M., \& Alloy, L. B. (2010). Dimensions of negative thinking and the relations with symptoms of depression and anxiety in children and adolescents. Cognitive Therapy and Research, 34, 333-342.

Schmitz, K. E., Hovell, M. F., Nichols, J. F., Irvin, V. L., Keating, K., Simon, G. M., et al. (2004). A validation study of early adolescents' pubertal self-assessments. Journal of Early Adolescence, 24, 357-384.

Segal, Z., Williams, J., \& Teasdale, J. (2002). Mindfulness-based cognitive therapy for depression. A new approach to preventing relapse. New York: The Guilford Press.

Skitch, S., \& Abela, J. R. Z. (2008). Rumination in response to stress as a common vulnerability factor to depression and substance misuse in adolescence. Journal of Abnormal Child Psychology, $36,1029-1045$.

Stone, L. B., Gibb, B. E., \& Coles, M. E. (2010). Does the hopelessness theory account for sex differences in depressive symptoms among young adults? Cognitive Therapy and Research, 34, 177-187.

Timbremont, B., \& Braet, C. (2001). Psychometrische evaluatie van de Nederlandstalige Children's Depression Inventory [Psychometric evaluation of the Dutch Children's Depression Inventory]. Gedragstherapie, 34, 229-242.

Timbremont, B., \& Braet, C. (2002). Children's Depression Inventory: Nederlandstalige versie [Children's Depression Inventory: Dutch version]. Lisse: Swets \& Zeitlinger.

Timbremont, B., Braet, C., \& Dreessen, L. (2004). Assessing depression in youth: Relation between the Children's Depression Inventory and a structured interview. Journal of Clinical Child and Adolescent Psychology, 33, 149-157.

Turner, J. J., \& Cole, D. (1994). Developmental differences in cognitive diatheses for child depression. Journal of Abnormal Child Psychology, 22, 15-32.

Wagner, C., Abela, J. R. Z., \& Brozina, K. (2006). A comparison of stress measures in children and adolescents: A self-report checklist versus an objectively rated interview. Journal of Psychopathology and Behavioral Assessment, 28, 251-261.

\section{Author Biographies}

Lea Rood is a Ph.D. student at the Department of Clinical Psychological Science of Maastricht University, The Netherlands. In 2003, she received her MA in Clinical and Health Psychology from Leiden University. Her major research interests include the role of rumination in the development of depressive symptoms in youth, affect regulation, and adaptive and maladaptive cognitive coping strategies in youth and adulthood.

Jeffrey Roelofs is an Assistant Professor at the Department of Clinical Psychological Science of Maastricht University, and Clinical Psychologist at the Mental Health Services department of Children and Youth. He received his Ph.D. in 2004 from Maastricht University. His major research interests include the role of attentional processes in the persistence of chronic low back pain, rumination, depression, autism, and treatment of internalizing disorders in youth.

Susan M. Bögels is a Full Professor at the Research Institute of Child Development and Education of University of Amsterdam and a 
Clinical Psychologist and Director of the UvA Treatment Centre for Parents and Children. She received her Ph.D. in 1994 from University of Groningen. Her major research interests include treatment effectiveness of disorders in youth, the role of the father in the development of child anxiety, and mindfulness interventions.

Cor Meesters is an Associate Professor at the Department of Clinical Psychological Science of Maastricht University. He received his
Ph.D. in 1995 from Maastricht University. His major research interests include developmental psychopathology, somatisation and depression in children, and assessment and correlates of autism spectrum disorders in adults and youth. 